\title{
ENSAIO
}

\section{SOBRE OS 45 ANOS DO PROGRAMA DE PÓS-GRADUAÇÃO EM EDUCAÇÃ̃ DA UNIMEP: UMA VITORIOSA EXPERIÊNCIA DE CONSOLIDAÇÃO DA PESQUISA}

\author{
ON THE 45 YEARS OF UNIMEP'S GRADUATE SCHOOL \\ OF EDUCATION: A VICTORY IN CONSOLIDATING RESEARCH
}

EN LOS 45 AÑOS DE LA GRADUATE SCHOOL
OF EDUCATION DE UNIMEP: UNA VICTORIA
EN LA CONSOLIDACIÓN DE LA INVESTIGACIÓN

ANTÔNIO JoAquim SEVERINO

Uninove

Resumo Trata-se de um breve depoimento, ao ensejo de comemoração dos 45 anos do PPGE da UNIMEP, com o sentido de lhe prestar uma homenagem, reconhecendo sua contribuição à pesquisa educacional brasileira e registrando algumas referências históricas de sua trajetória, com destaque para a participação na sua implantação aos professores Richard Senn e Joel Martins, bem como acenando para os desafios que continuam se colocando para o projeto educacional da pós-graduação, no mudado contexto sociocultural e político da atualidade.

Palavras-chave: Joel Martins; Richard Senn; Pesquisa; Pós-graduação.

Abstract As UNIMEP'S (Methodist University of Piracicaba) Graduate School of Education reaches its 45 th year, this paper presents a brief account of its history. I pay due homage to the School's contribution to Education research in Brazil and record some of the key participants in its foundation and development - especially professors Richard Senn and Joel Martins, who were instrumental during the School's implementation. Finally, I overview the challenges that the current social, cultural and political context in Brazil presents to a project of graduate study in Education.

Key-words: Joel Martins; Richard Senn; Research; Graduate school. 
Resumen Como el Programa de Post-Grado en Educación de Unimep (Universidad Metodista de Piracicaba) cumple 45 años, este documento presenta una breve reseña de su historia y rinde homenaje a su contribución a la investigación educativa en Brasil y registra algunos de los participantes clave en su fundación y desarrollo, especialmente los profesores Richard Senn y Joel Martins, que fueron fundamentales durante la implementación del Programa. Finalmente, presenta los desafíos que el actual contexto social, cultural y político de Brasil plantea a un proyecto de estudio de postgrado en Educación.

Palabras clave: Joel Martins; Richard Senn; Investigación; Escuela de postgrado.

\section{INTRODUÇÃo}

Participar da comemoração dos 45 anos deste PPGE é motivo de muita gratificação, pessoal e institucional, para quem já percorreu igual trajeto envolvido com esse grande, ambicioso e auspicioso projeto de implantação da pós-graduação em educação no país. Na década de 1970, um dos períodos mais tenebrosos de nossa história política recente, constituíamos, nos espaços acadêmicos, uma geração que depositava muitas esperanças na educação, em geral, e na pós-graduação, em particular. Víamos nesta um potencial muito fecundo, inclusive para a reconquista das liberdades civis, articuladas em torno da condição da cidadania e da democracia. Como ficou muito bem demonstrado em uma dissertação defendida nesse Programa, pela profa. Betty Antunes de Oliveira, o sistema de pós-graduação, criado pela ditadura militar com perspectivas eminentemente tecnocráticas, acabara, em pouco tempo, se transformando, contraditoriamente, num lugar de formulação de diagnósticos bem fundamentados, de críticas consistentes e de propostas alternativas para o reequacionamento da educação no país. Para além dessa perspectiva política e institucional, muito me gratifica ainda esta participação, na esfera de meus sentimentos pessoais, por fazer parte do grupo germinal desse programa, de cujo brilhante e significativo desenvolvimento posterior pude ser ainda testemunha, vendo como ele conquistou qualificadas vitórias de que nós, rústicos semeadores, só podemos nos orgulhar.

\section{A relevância da MeMória}

A volta ao tempo passado é necessidade para que se possa apreender a historicidade de nossas práticas e, por conseguinte, de toda a nossa existência. Pois estas se dão sempre como práxis histórico-sociais, ou seja, a nossa realidade concreta é sempre decorrente de um permanente processo de construção material e cultural, conduzido por um sujeito coletivo no decurso da temporalidade histórica. Não só nossos conhecimentos, mas igualmente nossas instituições e nossas ações se constituem como resultados das intervenções sobre os diversos setores da realidade objetiva, intervenções que fazemos sempre em coletividade, em consonância com projetos pensados e executados por conjuntos de pessoas, reunidas em torno de intencionalidades compartilhadas, por mais diferenciadas que possam ser as opções de cada indivíduo ou de cada grupo. Sob qualquer ângulo que a prática humana 
pode ser considerada, seja em sua dimensão técnica, em sua dimensão política ou em sua dimensão cultural, ela se desenrola na temporalidade histórica e na espacialidade social, num permanente processo de devir, num contínuo vir-a-ser. Por isso mesmo, seu processo real se realiza numa intrínseca relação dialética que articula o presente tanto ao passado como ao futuro. Sua concretude na atualidade, sua dinâmica no momento atual, têm vínculos profundos com os momentos já vencidos, já cristalizados em suas configurações, ao mesmo tempo em que se projetam no futuro, como exigências de novas configurações ainda não definidas. Em decorrência dessa condição de nossa prática, se quisermos avaliar suas expressões atuais, bem como projetar seus direcionamentos futuros, faz-se necessário resgatar sua história, mantendo viva sua memória, pois só ela pode nos fornecer, ao nos legar a posteriori um traçado objetivo e já trilhado, permite-nos aquilatar as conquistas e as perdas eventualmente ocorridas, possibilitando-nos assim efetivar um balanço significativo, com potencial para nos esclarecer sobre os caminhos futuros (SEVERINO, 2015).

Tal é o objetivo do presente artigo: fazer um breve depoimento pessoal buscando contribuir para o delineamento da memória da experiência do Programa de Pós-Graduação em Educação, da UNIMEP, aproveitando o ensejo da comemoração de seus 45 anos de existência. Sem dúvida, resgatar a memória de nossas práticas não é produzir mera exposição de fatos datados, mas sobretudo investir num diálogo em busca de novos sentidos para elas, para se enfrentar os problemas atuais, tentando superar soluções já vencidas, buscando-se inspirações que fecundem novos projetos.

\section{O LugAR DE ONDE FALO}

Sem dúvida, toda comemoração de aniversários dessa natureza tem seu sentido mais profundo numa dupla dimensão. É sempre um momento de rememoração, de resgate e de lembrança dos caminhos seguidos, dos obstáculos vencidos, das conquistas alcançadas, do sempre humano embate entre derrotas e vitórias. Por sua vez, é igualmente um momento de renovação dos propósitos e das finalidades, de uma renovada retomada de consciência da razão de ser que ocasionou o surgimento da iniciativa e que continua justificando a continuidade de sua intervenção histórica.

Certamente, não cabe aqui nesta minha fala de convidado retomar e reapresentar a já longa trajetória percorrida por esse Programa. Essa retomada já foi feita e está devidamente registrada em brilhantes relatos elaborados, em diversos momentos comemorativos, por alguém que a ele se ligou de maneira substantiva, ao longo de sua história, o Prof. Bruno Pucci, cuja vida se liga íntima e intensamente à história desse Programa. Refiro-me aos ricos textos que produziu com essa finalidade, textos que foram muito além da condição de meros relatos históricos de caráter narrativo. Em cada um deles, sempre se fez presente uma avaliação crítica e uma reflexão mais que pertinente sobre o projeto geral do ensino pós-graduado (PUCCI, 2003; 2011).

Por isso mesmo, de minha parte, ao compartilhar este festivo momento de comemoração, vou me ater apenas a duas referências a essa história. Primeiramente, retomando algumas 
considerações que já fizera quando da comemoração do $10^{\circ}$. aniversário do Programa. Em segundo lugar, relembrar duas figuras de grande importância para a história da pós-graduação.

\section{Dois grandes mentores: Joel Martins e Richard Senn}

O Programa se inaugurou compromissado com a perspectiva de abordar, analisar e propor a educação sob a consígnia da Filosofia. Isso foi um diferencial significativo. Graças à sua lucidez no âmbito das políticas educacionais, o Prof. Joel Martins propôs que iniciássemos o curso com área de concentração em Filosofia da Educação, entendendo-se esta não como uma explicitação teórica, essencialista ou positivista, da educação, mas como um olhar crítico a respeito da experiência educacional brasileira. E essa foi uma das marcas identitárias do Programa, sua vocação originária, a partir da qual se consolidou e ampliou seu leque de abertura à problemática educacional. Essa sensibilidade filosófica não comprometeu em nada a fecundidade da interação com as ciências que tomam a educação como seu objeto. Por sinal, a filosofia da educação não pode exercer-se consistentemente sem esse intercâmbio de mão dupla. Por isso mesmo, avalio a experiência quase cinquentenária desse Programa como a demonstração dessa efetiva parceria. Assim, os trabalhos científicos aqui desenvolvidos não se constituíram apenas como expressões metafilosóficas sobre a educação, mas como estudos de problemas educacionais abordados e explicados à luz de referências filosóficas. A perspectiva filosófica neles se fez presente à guisa de elemento esclarecedor, indicador de balizas para uma prática educativa que fosse compromissada com a necessária transformação qualitativa da sociedade.

E essa opção me pareceu muito devedora das intervenções desses dois protagonistas responsáveis pela implantação do Programa na UNIMEP. De um lado, o Dr. Richard Edward Senn, insigne gestor da área na Igreja Metodista norte-americana, encarregado de exercer sua gestão no IEP, bem como, a primeira reitoria da UNIMEP. Não se limitou a cumprir essa tarefa como mero administrador técnico; ao contrário, como eu o conheci, estava envolvido com os projetos do Prof. Joel Martins, dando continuidade à sua própria qualificação, fazendo o doutorado sob a orientação dele. Essa foi uma fecunda e profícua parceria. Imagino que não era fácil tomar decisões nessa linha no contexto da política geral da Igreja Metodista no Brasil. Como reitor da nascente UNIMEP, Dr. Senn, como o conhecíamos, abriu as portas da instituição para a implantação ainda pioneira da pós-graduação em Educação, e o fez acolhendo a proposta do Prof. Joel Martins, respeitando o seu viés filosófico.

\section{OS DESAFIOS CONTINUAM...}

O Brasil, nesse quadrante da segunda década do século XXI, há 45 anos da fundação do Programa, continua ainda atravessado por graves problemas na cultura e na educação, mantendo mais que nunca desafios muito fortes para a ação dos educadores e de todos as agências educadoras. No que concerne especificamente à educação institucional, são graves os problemas da educação infantil, média e superior, como é público e notório. A 
pós-graduação, apesar de ser quase um oásis em nosso contexto, também enfrenta desafios significativos, até porque ela não pulsa separada da totalidade do complexo processo educacional do país. Inclusive, tem responsabilidade ampliada no enfrentamento desses problemas. Daí a relevância de sua contribuição no diagnóstico de nossa crise e na sua necessária superação.

Assim, impregnando a realização de suas atribuições rotineiras, um curso de pós-graduação não pode perder de vista que se insere num processo mais amplo imanente à sua vocação geral. Essa vocação se vincula a suas finalidades intrínsecas, finalidades gerais que se embutem em todas as suas atividades particulares e que gostaria de especificar em quatro direções.

Em primeiro lugar, há que se manter fiel ao seu propósito mais evidente e palpável, que é o de produzir conhecimento novo na área. Afinal, a pós-graduação é lugar institucional prioritário de construção de conhecimento. Esse fim específico precisa ser indicado como a primeira finalidade, porque ele é o que gera uma demonstração material direta, concreta e visível, de mais fácil acesso por parte da comunidade. Ademais, é por esse seu produto que as demais finalidades podem ser identificadas e avaliadas. Tende-se até, às vezes, na comunidade, de se dar maior relevância a essa produção, como se vê no caso da aplicação do processo de avaliação do curso pelas agências oficiais, o que, obviamente, não cabe aqui discutir. $\mathrm{O}$ que cabe aqui é apenas lembrar o perfil que se espera desse conhecimento novo, bem como, as condições de sua produção que vão do rigor epistemológico à relevância social.

Em segundo lugar, a pós-graduação não pode perder de vista que, além de produzir conhecimento novo, lhe cabe também manter e ampliar o quadro de pesquisadores da área. É por isso que o seu perfil não é aquele de um instituto de pesquisa, em sentido estrito, eis que também precisa ser uma escola de formação de pesquisadores. Daí sua prática investigativa envolver necessariamente essa finalidade formadora, assumida de forma sistemática e intencional. Há que não se descuidar dessa tarefa, que tem natureza até mesmo de uma missão. E aqui também há que se levar em conta as exigências dessa formação do pesquisador, tendo-se bem claro que ela envolverá necessariamente rigor técnico-metodológico e fundamentação epistemológica, sem falar de outras exigências de natureza ética e política, todas implicadas no procedimento científico.

De um terceiro ponto de vista, a Pós-Graduação tem ainda por finalidade intrínseca consolidar, qualificar e aprimorar a formação profissional dos seus estudantes, com um duplo direcionamento: está em pauta a atividade profissional própria da área do curso, bem como aquela decorrente da potencialidade das mesmas em termos de docência no ensino superior. Isso quer dizer que a Pós-Ggraduação tem o papel do aprimoramento do exercício docente no ensino superior. E, no caso dos Programas da área educacional, acaba ocorrendo a junção dessas duas dimensões do trabalho profissional, uma vez que a docência é não apenas a esfera da intervenção didático-pedagógica do ensino mas a própria profissão do docente. Mas, mesmo no caso das demais profissões, o adequado seria assegurar um mínimo que fosse de mediações para o aperfeiçoamento das competências didático-pedagógicas dos seus profissionais, pois eles podem sempre ser solicitados para tarefas docentes. 
Mas há ainda uma quarta finalidade da Pós-Ggraduação que, apesar de menos visível, é igualmente de grande relevância, aguçada no caso da educação. Há que se esperar da Pós-Graduação um investimento sistemático, cuidadoso e intencional no amadurecimento de intelectuais para o desempenho de uma liderança no seio das suas comunidades sociais. Trata-se do preparo de líderes na intervenção sociocultural na vida da sociedade envolvente, pessoas que possam contribuir no debate dos problemas humanos que afligem toda a comunidade, intervenção que possa acontecer nos variados ambientes, institucionalizados ou não, onde venha se fazer ouvir.

\section{CONSIDERAÇões FinAIS}

Buscar o sentido da Pós-Graduação, em nosso contexto, pressupõe a referência lúcida e competente ao papel da ciência, da pesquisa e do ensino na sociedade brasileira. Trata-se de questão substantiva, de ponto nodal, pois é em função desse significado que se pode atribuir significação aos desdobramentos teóricos e aos investimentos práticos relacionados com a educação. Impõe-se considerar, preliminarmente, a exigência do compromisso do conhecimento com a relevância social. A legitimação de todos os processos e procedimentos relacionados com a educação está necessariamente vinculada aos valores e aos objetivos conectados com a construção de uma sociedade em que as pessoas possam encontrar subsídios para a sua emancipação. A Pós-Graduação não pode ser considerada fora desse contexto, como se estivesse desvinculada do compromisso da educação com um projeto de transformação da sociedade e de emancipação de todas as pessoas. Como qualquer segmento da educação, a Pós-Graduação, como lugar de produção de conhecimento, tem compromissos sociais e políticos com a compreensão e busca de soluções para os problemas cruciais enfrentados pela sociedade brasileira em cada área de conhecimento especificamente. $\mathrm{O}$ avanço do conhecimento deve ser articulado à investigação de problemas socialmente relevantes, considerando as demandas da sociedade brasileira.

Assim, no que concerne à realidade brasileira, esse compromisso de contribuir para a construção de uma nova sociedade implica conceber e praticar a ciência e a educação de modo a fazer delas instrumentos da emancipação humana, tanto no plano pessoal como no plano coletivo, levando-se em conta as precárias condições de existência em que ainda se encontra a maioria da população brasileira. São bem conhecidas as carências que marcam a nossa sociedade, seja no âmbito da situação socioeconômica, seja no universo das relações políticas ou na esfera da cultura simbólica.

Deve ser, pois, sua obrigação privilegiar temáticas e objetos socialmente relevantes, engajando os pós-graduandos, seus professores e o próprio Programa como lugar institucional de produção de conhecimento, como sujeito social e coletivo que é, na finalidade intrínseca e imanente do conhecimento: contribuir para a emancipação dos homens, investindo nas forças construtivas das práticas reais mediadoras da existência histórica.

A inclusão, pela Capes, de um novo quesito em seu modelo de avaliação dos Programas, qual seja, a inserção social, relança o debate acerca do impacto que a ciência e a pes-

Comunicações $\mid$ Piracicaba $\mid$ v. $25 \mid$ n. $3 \mid$ p. 341-347| set.-dez. 2018 
quisa devem ter sobre a sociedade. Tem-se insistido que à Pós-Graduação cabe enriquecer e aprimorar não apenas a ciência, mas também a sociedade, que o conhecimento, a ciência, a pesquisa devem produzir resultados que contribuam para a transformação qualitativa da sociedade. E se busca mostrar que não basta sustentar que toda ciência, pelo simples fato de ser boa ciência, rigorosa e competente, já estaria tendo impacto social, criando cultura. É preciso mais que isso, é preciso que o fazer da Pós-Graduação articule temática, formação científica e transformação social, de tal modo que o saber acadêmico alcance a dinâmica da vida social. Mas isso sem se transformar em doutrinação ideologizada, mantendo sua condição específica de conhecimento que esclarece e intencionaliza a realidade humana envolvente (SEVERINO, 2015).

\section{REFERÊNCIAS}

PUCCI, BRUNO. Ano 38. Piracicaba: Unimep, 2011 (http://www.unimep.br/ bpucci/ PPGE_38anos.pdf)

PUCCI, Bruno. Marcas/Marcos de uma História. Comunicações. UNIMEP, v. 10, n. 2, 2003, p. 113-121.

SEVERINO, Antonio J. Trajetos da pós-graduação em educação no Brasil: um testemunho pessoal. In: BAPTISTA, Ana M. Haddad et al. (Orgs.). Tempo-Memória na educação: reflexões. São Paulo: BT Acadêmica, 2015, p. 89-106.

\section{Antonio Joaquim Severino}

É bacharel e mestre em Filosofia pela Université Catholique de Louvain; doutor em Filosofia, pela PUCSP; livre-docente e titular em Filosofia da Educação, pela FE-USP; professor aposentado de Filosofia da Educação na Faculdade de Educação da USP; é atualmente docente pesquisador junto ao PPGE da Universidade Nove de Julho, em São Paulo.

Submetido em: 15-6-2018

Aceito em: 25-6-2018 